\title{
Penerapan M-Banking Dalam Meningkatkan Jasa Dan Layanan Perbankan Di PT. Bank Pembangunan Daerah Sumatera Barat Cabang Siteba
}

\author{
Diana Febri Ayunisa ${ }^{1)}$, Muhammad Hendra ${ }^{2)}$ \\ Akademi Keuangan dan Perbankan "Pembangunan” AKBP Padang \\ dianaayu2202@gmail.com
}

\begin{abstract}
The purpose of this study was to determine the application of m-banking in improving banking service and service at PT. Bank Pembangunan Daerah Sumatera Barat Cabang Siteba. This study uses qualitative data analysis as a research method that describes descriptively about the application of m-banking in improving banking service and services at PT. Bank Pembangunan Daerah Sumatera Barat Cabang Siteba. The results of this study indicate that the application of m-banking makes it easier for customers to carry out financial and non-financial transactions, so that customers are interest in using nagari m-banking features such as nagari info, nagari transfer, nagari QR and nagari admin can provide convenience to customers, without have to come to the bank, and without having to queue at the bank.
\end{abstract}

Keywords: M-Banking, services, Service, Banking

\section{PENDAHULUAN}

Kemajuan dan perkembangan teknologi yang diiringi dengan perkembangan sistem informasi berbasis teknologi terjadi begitu pesat di era globalisasi ini. Dengan adanya teknologi modern, masyarakat dapat memanfaatkan teknologi modern dengan lebih baik, Menyadari semakin ketatnya persaingan yang terjadi di dunia bisnis dimasa ini, menuntut setiap perusahaan untuk lebih serius dan bekerja keras dalam usaha memenangkan persaingan tentunya sebuah perusahaan, haruslah mampu membaca peluang dan memenuhi keinginan yang diharapkan oleh konsumen (Amelia \& Dona, 2012). Dengan perkembangan teknologi yang semakin maju dan modern, permintaan akan komunikasi yang efektif dan efisien terus berkembang, oleh karena itu banyak orang berharap untuk menciptakan alat yang dapat membantu manusia mengatasi masalah komunikasi, sehingga terciptalah internet. Internet yang juga di manfaatkan kalangan orang maupun organisasi untuk berbisnis. Khusus bagi bank, salah satu bentuk layanan yang dikembangkan oleh bank adalah layanan perbankan online banking. Perbankan online adalah layanan transaksi perbankan yang dapat dilakukan oleh nasabah di rumah, tempat usaha, atau lokasi lain yang tidak berada di lokasi (cabang) bank yang sebenarnya. Dengan menggunakan media komunikasi, seperti computer, telepon seluler, dan telepon rumah. Bentuk layanan perbankan berbasis online tersebut antara lain berupa Automatic Teller Machine (ATM) dan electronic banking (e-banking) (Irmadhani \& Adhi, 2012).

Menurut (Fadlan, 2018) Mobile Banking adalah tindakan melakukan transaksi keuangan online dengan bantuan perangkat telekomunikasi mobile seperti ponsel atau 
tablet. Melalui ponsel, pengguna perbankan dapat mengakses layanan keuangan dan non keuangan seperti manajemen rekening, informasi saldo, pemindahan, pembayaran tagihan, perubahan PIN dan permitaan buku cek.

PT. Bank Pembangunan Daerah Sumatera Barat Cabang Siteba merupakan salah satu bank pembangunan daerah yang memberikan pelayanan bagi setiap nasabahnya. Dalam upaya meningkatkan layanan, pada tahun 2018 PT. Bank Pembangunan Daerah Sumatera Barat Cabang Siteba mengeluarkan suatu layanan yang dapat mempermudah nasabahnya dalam melakukan transaksi yaitu Nagari Mobile Banking, Nagari mobile banking merupakan jasa layanan transaksi keuangan perbankan yang dapat diakses dengan menggunakan handphone seluler berbasis internet, Nagari mobile banking dapat diakses kapanpun dan dimanapun, sehingga nasabah tidak memiliki batas atau hambatan dalam melakukan transaksi. Nagari mobile banking menyediakan fitur yang cukup beragam, salah satunya yaitu fitur transfer, nasabah dapat melakukan transfer dana baik kesesama nasabah bank Nagari maupun ke nasabah bank lainnya dan juga nasabah bank Nagari juga dapat melakukan pembayaran dan pembelian, seperti pembelian token listrik, pembayaran perusahaan daerah air minum (PDAM) dan fintect lainnya. Dengan adanya mobile banking ini diharapkan nasabah terus dapat meningkatkan kepuasannya dalam menggunakan bank Nagari sebagai bank utama dalam melakukan transaksi keuangan maupun non keuangan (Putri \& Susanto, n.d).

Selain itu transaksi dengan m-banking juga dapat membantu mengurangi masalah dan hambatan yang ada pada umumnya sering terjadi pada sistem pelayanan manual perbankan seperti banyaknya nasabah yang akan melakukan transaksi karena pada umumnya bank menerapkan sistem antrian berdasarkan nomor urut antrian sehingga dibutuhkan banyak waktu untuk melakukan suatu transaksi. Selain itu masalah lain yang sering terjadi dan menghambat dalam proses transaksi manual adalah sering terganggunya sistem jaringan (offline) yang menyebabkan pelayanan menjadi lambat bahkan terhenti. Produk-Produk m-banking yang digunakan di PT. Bank Pembangunan Daerah Sumatera Barat Cabang Siteba antara lain adalah :

\section{Tabel 1}

Produk-Produk M-Banking yang ada di PT. Bank Pembangunan Daerah Sumatera Barat Cabang Siteba

\begin{tabular}{lc}
\hline No & Produk-Produk M-Banking \\
\hline 1 & Kartu ATM/Debit Gold \\
2 & SMS Banking \\
3 & SMS Notifikasi \\
4 & Virtual Account \\
5 & NCM (Nagari Cash Management) \\
\hline
\end{tabular}

Sumber:https://ww.banknagari.co.id

Berikut ini adalah jumblah pengguna $m$-banking dan jumblah nasabah PT. Bank Pembangunan Daerah Sumatera Barat Cabang Siteba Tahun 2018-2020. 


\section{Tabel 2}

Jumlah Pengguna Mobile Banking dan Jumlah Nasabah Bank Nagari Cabang Siteba Tahun 2018 sampai 2020

\begin{tabular}{ccc}
\hline Periode & Pengguna Mobile Banking & Jumlah Nasabah \\
\hline 2018 & 409 & 11672 \\
2019 & 785 & 37550 \\
2020 & 480 & 37426 \\
\hline
\end{tabular}

Sumber: PT. Bank Pembangunan Daerah Sumatera Barat Cabang Siteba

Menyadari akan pentingnya manfaat dan kemudahan bertransaksi dengan menggunakan fasilitas m-banking guna minimalisir masalah dan hambatan-hambatan dalam pelayanan perbankan yang dilakukan secara manual di PT. Bank Pembangunan Daerah Sumatera Barat Cabang Siteba maka penulis tertarik untuk melakukan penelitian mengenai minat nasabah dalam menggunakan fasilitas $m$-banking.

\section{METODE PENELITIAN}

Metode penelitian yang digunakan: 1) Penelitian Perpustakaan (Library Research), Yaitu melakukan pengumpulan data melalui cara mempelajari teori-teori dari literatur dan buku-buku yang ada hubungannya dengan objek penelitian. 2) Penelitian Lapangan (Field Research), Yaitu penelitian ini dilakukan dengan cara pengamatan lansung dan melakukan wawancara dengan pihak-pihak yang terkait.

Untuk menganalisa data penelitian penulis menggunakan analisa data kualitatif sebagai metode penelitian yang menjelaskan secara deskriptif mengenai penerapan $m$ banking dalam meningkatkan jasa dan layanan perbankan di PT. Bank Pembangunan Daerah Sumatera Barat Cabang Siteba.

\section{HASIL DAN PEMBAHASAN Pengertian Perbankan}

Menurut (Kasmir, 2013), Perbankan adalah kegiatan menghimpun dana (funding) dan menyalurkan dana (Landing). Sedangkan menurut (Darmawi, 2012), pengertian perbankan adalah segala sesuatu yang menyangkut bank, mencakup kelembagaan, kegiatan usaha, serta cara dan proses dalam melaksanakan kegiatan usahanya. Dapat dismpulkan bahwa perbankan adalah segala sesuatu yang berhubungan dengan bank, dan segala sesuatu yang berhubungan dengan bank yang meliputi kelembagaan, kegiatan usaha, serta cara dan proses dalam melakukan kegiatan usaha.

\section{Jasa Perbankan}

Jasa bank adalah semua aktifitas bank, baik secara lansung maupun tidak lansung yang berkaitan dengan tugas dan fungsi bank sebagai lembaga intermediasi, yaitu lembaga yang memperlancar terjadinya transaksi perdagangan, memperlancar peredaran uang, dan memberikan jaminan kepada nasabahnya (Indonesia \& Perbankan, 2013).

\section{Layanan}

Menurut (Safitri \& Marlius, 2018) defenisi pelayanan adalah setiap tindakan atau kegiatan yag dapat ditawarkan oleh suatu pihak kepihak lain, yang pada dasarnya 
tidak berwujud dan tidak mengakibatkan kepemilikan apapun. Pelayanan merupakan perilaku produsen dalam rangka memenuhi kebutuhan dan keinginan konsumen demi tercapainya kepuasan konsumen itu sendiri.

\section{Pengertian Mobile Banking}

Menurut (Putri \& Susanto, n.d.) M-Banking merupakan suatu fasilitas yang disediakan oleh penyedia jasa atau bank yang dapat mempermudah masyarakat dalam melakukan transaksi keuangan maupun non keuangan dengan menggunakan perangkat atau handphone yang berbasis internet.

\section{Pembahasan}

Penerapan M-Banking Dalam Meningkatkan Jasa Dan Layanan PT. Bank Pembangunan Daerah Sumatera Barat Padang Cabang Siteba.

Pelayanan yang berkualitas tidak hanya sekedar memberikan pelayanan, tetapi juga membutuhkan sedikit jasa yang lebih menarik sehingga bisa memenuhi minat nasabah yang mengharapakan pelayanan yang terbaik. Kualitas pelayanan sangat penting bagi bank, nasabah dan pegawai bank lainnya, karena dapat mempertahankan dan menjaga loyalitas nasabah.

Dengan semakin berkembangnya di dunia perbankan, bank harus memperkuat dalam memberikan pelayanan dan jasanya kepada nasabah. Untuk meningkatkan minat nasabah kepada PT. Bank Pembangunan Daerah Sumatera Barat Cabang Siteba memberikan kemudahan bertransaksi kepada nasabah, adanya transaksi finansial ataupun non-finansial yaitu dengan menerapkan M-Banking.

M-Banking merupakan salah satu produk yang diluncurkan oleh PT. Bank Pembangunan Daerah Sumatera Barat Cabang Siteba yang berguna untuk mempermudah nasabah dalam bertransaksi. Sehingga nasabah tidak harus datang lagi ke kantor maupun ke mesin ATM untuk melakukan sebuah transaksi. Seperti yang kita ketahui, M-banking mempunyai sasaran untuk menciptakan, memperbaiki dan mempertahankan nasabah. Sehingga sangat mendukung dalam menghasilkan keuntungan bagi bank.

Penerapan m-banking dalam meningkatkan jasa dan layanan bank di PT. Bank Pembangunan daerah Sumatera Barat Cabang Siteba. Bank menyediakan produk $m$ banking yang bisa digunakan lansung oleh nasabah yang bertujuan untuk mempermudah nasabah dalam melakukan sebuah transaksi dimana nasabah tidak perlu lagi mengantri di Bank untuk melakukan transaksi atau mendapatkan pelayanan yang kurang cepat oleh teller ataupun customer service. Bank memberikan berbagai macam fitur untuk nasabah supaya nasabah berminat dalam menggunakan $m$-banking, seperti fitur pengecekan saldo, fitur transfer, baik antara sesama rekening maupun antar bank, fitur transaksi keuangan dengan menggunakan QR fitur Nagari Pembayaran (payment), fitur Nagari Prabayar (prepaid) dan fitur Nagari Admin. Fitur-fitur m-banking sebagai berikut:

\section{Fitur-Fitur Nagari Mobile Banking}

Dalam upaya menarik minat nasabah, bank memberikan kemudahan transaksi bagi nasabahnya, memberikan beberapa fitur yang dapat diakses oleh nasabah dari handphone mereka sebagai berikut: 


\section{a. Nagari Info}

Nagari m-banking memiliki beberapa fitur yang dapat mempermudah nasabah dalam melakukan transaksi, agar nasabah tidak perlu datang kekantor ataupun gerai ATM dalam bertransaksi. Nagari m-banking memiliki fitur Nagari Info, fitur ini untuk membantu aktivitas transaksi yang dilakukan oleh nasabah, fitur Nagari Info terdiri dari tiga (3) sub-fitur yaitu sebagai berikut:

1). Info Saldo

Fitur ini dapat membantu nasabah dalam melakukan pengecekan saldo rekening, nasabah dapat memastikan saldo yang tersisa setelah melakukan transaksi atau mendapatkan transaksi dana dari rekening lainnya.

2)Pemberitahuan

Fitur ini merupakan notifikasi yang dapat dilihat oleh nasabah setelah melakukan transaksi pada Nagari m-banking, dengan fitur ini nasabah dapat memastikan transaksi yang dilakukan berhasil atau tidak.

3). Info 10 Transaksi Terakhir

Fitur ini berisikan data transaksi 10 transaksi terakir, baik transaksi penarikan, transfer, pembayaran maupun transaksi pembelian. Dengan adanya fitur Nagari Info ini, nasabah juga dapat mengetahui transaksi apa saja yang sudah dilakukan dalam fitur pemberitahuan dan 10 transaksi terakhir.

\section{b. Nagari QR}

Nagari QR merupakan bentuk transaksi menggunakan kode batang untuk mempermudah dalam melakukan transaksi, hanya melakukan scan terhadap kode batang yang dituju. Selain fitur Nagari Info, Nagari m-banking juga memiliki fitur Nagari QR, fitur ini dapat digunakan nasabah dalam transaksi non-tunai dengan melakukan scan kode batang, fitur Nagari QR terdiri dari dua (2) sub-fitur yaitu sebagai berikut:

1). Pembayaran dengan kode $Q R$

Pembayaran dengan kode QR merupakan fitur baru yang dikeluarkan PT. Bank Pembangunan Daerah Sumatera Barat untuk mempermudah nasabah dalam melakukan pembayaran, sehingga pembayaran data dilakukan dengan cepat dan aman.

2) Transfer dengan kode $Q R$

Transfer dengan kode QR dapat mempercepat proses transaksi transfer antar sesama rekening Nagari, dengan hanya menscan kode batang rekening tujuan, maka transfer dapat dilakukan dan berhasil masuk kedalam rekening tujuan transfer Nasabah dapat melakukan scan kode batang pada fintect yang sudah bekerja sama dengan PT. Bank Pembangunan Daerah Sumatera Barat Cabang Siteba, sehingga dapat meminimalisir penggunaan cash dalam bertransaksi, selain itu dengan adanya fitur Nagari QR nasabah dapat melakukan pembayaran zakat yang bekerja sama dengan QRIS, pembayaran zakat dapat dilakukan dengan cepat dan mudah.

\section{c. Nagari Transfer}

Nagari transfer merupakan fitur yang dapat digunakan nasabah dalam melakukan transfer dana, fitur ini dilindungi dengan tingkat keamanan yang tinggi, selain masuk menggunakan kode akses, sebelum persetujuan melakukan transfer, nasabah harus memasukan password sebagai kode keamanan dan persetujuan transfer. 
Nagari Transfer merupakan salah satu fitur yang terdapat dalam Nagari m-banking. Dalam Nagari Transfer terdapat tiga (3) sub-fitur sebagai berikut ini:

1) Antar Rekening

Fitur antar rekening merupakan fitur transfer yang dapat dilakukan sesama rekening Nagari. Nasabah yang ingin melakukan transfer ke rekening Nagari lainnya dapat menggunakan fitur ini agar transfer dapat dilakukan dengan cepat.

2) Antar Bank

Fitur antar bank merupakan fitur transfer yang dapat dilakukan kepada pemilik rekening bank lainnya, dengan adanya fitur ini dapat meningkatkan mobilitas nasabah dalam melakukan transfer ke bank lainnya.

3) Virtual Account

Fitur virtual account merupakan fitur transfer dana atau pembayaran kepada rekening virtual milih perseorangan maupun lembaga dengan menyertakan nomor virtual account tujuan penerimaan. Nagari transfer merupakan salah satu fitur utama yang terdapat dalam Nagari m-banking, dengan adanya fitur ini, nasabah dalam melakukan transfer dengan cepat dan aman tanpa harus datang kekantor cabang bank maupun gerai ATM, transfer dapat dilakukan kapanpun dan dimanapun, selain dapat melakukan transfer antar sesama rekening bank lainnya yang terdaftar di Bank Indonesia, selain itu Nagari transfer juga dapat melakukan transfer maupun pembayaran melalui virtual account, baik milik perorangan maupun non-perorangan dengan mengisikan nomor virtual account tujuan.

d. Nagari Admin

Nagari admin merupakan fitur bantuan yang terdapat pada Nagari m-banking, fitur ini membantu nasabah untuk mengetahui bukti transaksi dan pengaturan terhadap akun Nagari $m$-banking,.

Dalam setiap akun m-banking, memiliki fitur bantuan untuk mempermudah nasabah dalam melakukan pengelolaan maupun kontak terhadap akun $m$-banking, tidak terkecuali Nagari m-banking, berikut ini beberapa sub-fitur yang terdapat di Nagari Admin. Sebagai Berikut:

1) Bukti transaksi

Setiap nasabah dalam melakukan transaksi memiliki bukti atas transaksi tersebut, baik transaksi transfer, pembayaran dan transaksi lainnya, bukti tersebut dapat dikirim kepada akun lain atau orang lain tempat nasabah melakukan transaksi sebagai buku bahwa transaksi telah berhasil dilakukan,

2) Pengaturan

Fitur ini merupakan fitur yang dapat digunakan oleh nasabah untuk mengatur dan mengelola akun Nagari m-bankingnya, dengan fitur ini nasabah dapat mengganti PIN, Kode Akses secara berkala untuk menjaga keamanan akun dari tindakan penyalahgunaan oleh pihak yang tidak bertanggung jawab.

Nagari admin merupakan fitur yang disediakan oleh Nagari m-banking bagi setiap nasabahnya agar nasabah dapat melakukan kontrol dan pengelolaan demi keamanan akun m-banking nasabah, nasabah dapat memperoleh bukti atas setiap transaksi yang diperoleh dan dikirim kepada orang lain atau perusahaan sebagai bukti bahwa transaksi telah berhasil dilakukan selain itu dalam fitur juga memungkinkan para nasabah untuk mengganti PIN dan kode akses untuk menjaga keamanan akun. 


\section{Prosedur Pendaftaran M-Banking pada PT. Bank Pembangunan Daerah Sumatera Barat Cabang Siteba}

Bagi nasabah atau calon nasabah, dapat mendaftarkan rekening mereka untuk mendapatkan kemudahan dalam bertransaksi dengan menggunakan m-banking, bagi nasabah baru, maka prosedur yang harus dilakukan sebagai berikut:

a. Melakukan pembukaan buku rekening dengan syarat foto copy KTP

b. Megisi Formulir permohonan pembukaan rekening yang ditanda tangani oleh nasabah,

c. Setelah rekening nasabah selesei, maka nasabah akan mengisi form untuk pengaktifan m-banking.

d. Setelah rekening nasabah selesei, maka nasabah akan mengisi form untuk pengaktifan m-banking.

e. Nasabah diminta untuk melakukan pengunduhan aplikasi Nagari $m$-banking di Play Store ataupun Apple Store.

f. Kemudian costumer service melakukan pengaktifan m-banking pada sistem perusahaan dengan melakukan aktifasi melalui nomor handphone yang terdaftar.

g. Nasabah mengisi PIN dan Kode Akses untuk keamanan rekening nasabah.

h. Nagari m-bangking aktif dan siap untuk digunakan.

\section{Upaya Peningkatan Jasa dan Layanan Melalui M-Banking}

PT. Bank Pembangunan Daerah Sumatera Barat Cabang Siteba merupakan produk keuangan dalam bentuk perbankan yang dimiliki oleh pemerintah Sumatera Barat. Dengan semakin meningkatnya perkembangan perbankan, untuk itu PT. Bank Pembangunan Daerah Sumatera Barat Cabang Siteba juga melakukan inovasi untuk meningkatkan pelayanan kepada para nasabahnya dalam bentuk $m$-banking, Berikut ini upaya peningkatan layanan melalui fitur-fitur Nagari Mobile Banking.

a. Nagari Info

Dengan adanya fitur ini PT. Bank Pembangunan Daerah Sumatera Barat Cabang Siteba memberikan pelayanan dan kemudahan bagi setiap nasabahnya untuk mengetahui jumblah saldo yang ada di dalam rekening, sehingga nasabah dapat melakukan akses dengan mudah dan cepat untuk mengetahui info saldo rekening dimanapun dan kapanpun, Selain itu nasabah juga dapat mengetahui informasiinformasi atas transaksi yang telah dilakukan nasabah.

b. Nagari QR

Nagari QR merupakan produk atau fitur terbaru yang diluncurkan oleh PT. Bank Pembangunan Daerah Sumatera Barat awal tahun 2020, fitur ini diharapkan dapat mempermudah nasabah dalam melakukan pembayaran dan transfer melalui scan kode batang sehingga transaksi pembayaran dan transfer dapat dilakukan dengan cepat dan aman, Selain ini PT. Bank Pembangunan Daerah Sumatera Barat Cabang Siteba juga telah bekerja sama dengan berbagai macam fintech lainnya guna memperluas jangkauan transaksi seperti pembayaran adira finance. Dengan adanya fitur ini diharapkan nasabah terus meningkatkan jumblah transaksinya dengan menggunakan Nagari Mobile Banking. 


\section{c. Nagari Transfer}

PT. Bank Pembangunan Daerah Sumatera Barat Cabang Siteba terus berupaya meningkatkan pelayanan kepada setiap nasabahnya, tidak terkecuali dalam mempermudah nasabah dalam melakukan transfer, baik transfer kepada sesame rekening Nagari maupun rekening bank lainnya, dengan adanya fitur Nagari transfer ini, nssabah dapat melakukan transfer dengan kapanpun dan dimanapun dengan cepat. d. Nagari Admin

Nagari Admin merupakan salah satu fitur yang terdapat pada Nagari $m$ banking, fitur ini dapat digunakan untuk membantu nasabah memperoleh bukti atas transaksi yang telah dilakukan dan mengirim bukti tersebut kepada pihak lain sebagai bukti bahwa transaksi telah berhasil dilakukan, selain itu dalam fitur Nagari Admin ini, nasabah juga dapat melakukan penggantian PIN dan Kode Akses untuk menjaga keamanan akun Nagari $m$-banking nasabah dari penyalah gunaan pihak yang tidak bertanggung jawab. Dengan adanya fitur ini nasabah lebih merasa aman dalam menggunakan Nagari Mobile Banking.

Perkembangan M-Banking Dari Tahun 2018-2020

Berikut ini adalah tabel tentang perkembangan jumlah penguna $m$-banking dan jumlah nasabah PT. Bank Pembangunan Daerah Sumatera Barat Cabang Siteba Tahun 2018-2020.

\section{Tabel 3.2}

Perkembangan Mobile Banking dan Jumlah Nasabah Bank Nagari Cabang Siteba Tahun 2018 sampai 2020

\begin{tabular}{ccccc}
\hline \multirow{2}{*}{ Tahun } & $\begin{array}{c}\text { Pengguna } \text { M- Banking } \\
\text { Perubahan }\end{array}$ & \multicolumn{2}{c}{ Jumlah Nasabah } \\
& Jumlah & Jumlah & Perubahan \\
\hline 2018 & 409 & $91,93 \%$ & 11672 & \\
2019 & 785 & $38,85 \%$ & 37550 & $22,17 \%$ \\
2020 & 480 & 37426 & $3,302 \%$ \\
\hline
\end{tabular}

Sumber: Data diolah oleh peneliti.

Berdasarkan dari keterangan tebel diatas, pada Tahun 2018 pengguna mobile banking sebesar 409 dari jumblah nasabah Bank Nagari Cabang Siteba sebanyak 11672. Sedangkan pada Tahun 2019, terjadi peningkatan jumblah pengguna $m$-banking sebesar 785 atau 91,93\% dan jumblah nasabah pun meningkat sebanyak 37550 atau 22,17\% Selanjutnya pada Tahun 2020 terjadi penurunan pengguna $m$-banking sebesar 480 atau $38,85 \%$, begitupun dengan jumblah nasabah juga sedikit menurun sebanyak 37426 atau $3,302 \%$.

Perubahan dari nasabah ditahun 2018 ke 2019 mengalami peningkatan karena memakai m-banking nasabah memiliki banyak keuntungan dari menggunakan fasilitas ini, $m$-banking praktis digunakan melalui handphone, hemat waktu, dan biaya. Namun ditahun 2020 nasabah m-banking mengalami penurunan disebabkan karena sering terjadinya kerusakan jaringan internet pada saat nasabah melakukan transaksi, terutama nasabah yang menggunakan $m$-banking dari pelosok desa yang membuat nasabah susah dalam bertransaksi menggunakan aplikasi m-banking. Jadi untuk 
meningkatkan minat nasabah kembali dengan menggunakan aplikasi ini pemerintah diharapkan dapat memperluas jaringan.

\section{Manfaat M-Banking}

M-Banking memiliki manfaat yang cukup banyak bagi penggunanya yaitu, sebagai berikut:

a. Bagi bank dapat mengurangi biaya operasional seperti: biaya kertas, biaya percetakan, biaya alat tulis dan lain-lain.

b. Transaksi Real Time, Kapanpun dimanapun (berdasarkan jaringan operator telekomunikasi).

c. Lebih hemat karena menggunakan jaringan data.

d. Setiap transaksi menggunakan PIN yang hanya diketahui nasabah.

e. Mempermudah nasabah bank, dimana nasabah tidak perlu datang ke bank atau mesin ATM untuk melakukan transaksi seperti cek saldo, transfer, cek transaksi, membayar tagihan dan lain-lain kecuali untuk transaksi setoran tunai atau penarkan tunai.

f. Bagi bank dapat mengurangi jumblah karyawan atau staf operasional sehingga penggunaan ruangan lebih dapat diefisienkan.

\section{SIMPULAN}

Berdasarkan uraian yang telah dikemukakan pada bab-bab terdahulu. Maka penulis dapat menyampaikan beberapa kesimpulan tentang Penerapan m-banking dalam meningkatkan jasa dn layanan perbankan di PT. Bank Pembangunan Daerah Cabang Siteba adalah sebagai berikut:

1. Secara umum PT. Bank Pembangunan Daerah Sumatera Barat terus meningkatkan layanan kepada setiap nasabahnya agar nasabah terus aktif dan meningkatkan transaksi meggunakan Nagari $M$-Banking, dengan adanya aplikasi Nagari $M$ Banking dapat mempermudah nasabah dalam melakukan transaksi, baik transaks keuangan maupun transaksi non-keuangan.

2. Penerapan M-banking bagi nasabah yaitu memberikan kenyamanan bagi penggunanya, tanpa datang ke bank, tampa harus mengantri dan bagi pihak bank M-banking memberikan keuntungan financial maupun citra dimana nasabahnya.

3. Dengan adanya fitur Nagari QR, mempermudah nasabah dalam melakukan pembayaran zakat, karena PT. Bank Pembangunan Daerah Sumatera Barat. Bekerja sama dengan QRIS, sehingga pembayaran zakat dapat dilakukan dengan cepat dan mudah.

4. Dari tahun 2018 sampai 2020 jumblah pengguna M-banking mengalami peningkatan, akan tetapi tidak signifikan, jika dibandingkan dengan jumblah keseluruhan nasabah Bank Nagari Cabang Siteba yang dari tahun ke tahun mengalami peningkatan yang cukup pesat.

5. Yang terpenting M-banking adalah memberikan yang terbaik dengan selalu menjaga kualitas produk dan kepuasan pelanggan demi kelangsungan Perusahaan. Walaupun Pengguna $M$-banking tidak sebanyak dari jumblah nasabah di Bank Nagari Cabang Siteba tetapi dengan adanya M-banking Bank Nagari Siteba juga berkembang sesuai dengan perkembangan zaman saat ini. Dengan pelayanan yang telah distandarkan oleh Bank Nagari Cabang Siteba maka dengan itulah wujud dari 
service Exellen Perusahaan PT. Bank Pembangunan Daerah Sumatera Barat Cabang Siteba.

\section{UCAPAN TERIMA KASIH}

Penulis ucapkan puji dan syukur atas kehadirat Allah SWT, yang telah melimpahkan rahmat dan hidayah kepada penulis. Penulis ingin mengucapkan terima kasih kepada PT. Bank Pembangunan Daerah Sumatera Barat Cabang Siteba.

\section{DAFTAR PUSTAKA}

Amelia, T. P., \& Dona, E. (2012). Penerapan E-Banking Dalam Meningkatkan Jasa dan Pelayanan Perbankan PT.Bank Mandiri Kantor Cabang Padang. 1-9.

Darmawi, H. (2012). Manajemen Perbankan. Manajemen Perbankan. Jakarta: Bumi Aksara

Fadlan, A. (2018). Pengaruh Persepsi Kemudahan Persepsi Kegunaan Terhadap Penggunaan Mobile Banking (Studi Pada Mahasiswa Pengguna Mobile Banking Universitas Brawijaya). 121.

Bank Indonesia, (2013). Memahami Bisnis Bank. PT. Gramedia Pustaka Utama Kompas Gramedia Building Blok 1, Lt.5 Jl. Palmerah Barat 29-37 Jakarta 10270 www.gramediapustakautama.com

Irmadhani, \& Adhi, M. N. (2012). Pengaruh persepsi kebermanfaatan, persepsi kemudahan penggunaan dan. Pengaruh Persepsi Kebermanfaatan, Keamanan, Kepercayaan Dan Persepsi Kemudahan Penggunaan Terhadap Penggunaan Online Banking Pada Mahasiswa S1 Fakultas Ekonomi Universitas Negeri Yogyakarta, 1-20.

Kasmir, D. (2013). Bank Dan Lembaga Keuangan Lainnya. http://www.rajagrafindo.co.id

Putri, A. R., \& Susanto, R. (n.d.). Penerapan M-Banking Dalam Meningkatkan Jasa Dan Layanan Perbankan Di PT. Bank Pembangunan Daerah Sumatera Barat Cabang Siteba.

Safitri, R. N., \& Marlius, D. (2018). Penerapan E-Banking Dalam Meningkatkan Jasa Dan Layanan Perbankan Di Pt. Bank Rakyat Indonesia Cabang Padang. 1-9. https://doi.org/10.31227/osf.io/gkv8t 